\title{
Study on the Problems in Special-Contracted Teachers' Professional Development
}

\author{
Yali Zhang \\ School of Pedagogy, Southwest University, Chongqing, China \\ Email: 459761300@qq.com
}

Received 27 July 2015; accepted 25 August 2015; published 28 August 2015

Copyright (C) 2015 by author and Scientific Research Publishing Inc.

This work is licensed under the Creative Commons Attribution International License (CC BY). http://creativecommons.org/licenses/by/4.0/

c) (i) Open Access

\begin{abstract}
Special-contracted teachers' scheme, conducted by the central government, is a policy which aims to supply teachers for compulsory education in western China. A large number of special-contracted teachers are recruited in Guizhou province. Research method of investigation is used in this study. The purpose is finding the problems of professional development of special-contracted teachers and looking for the suggestions for the professional development of special-contracted teachers.
\end{abstract}

\section{Keywords}

Continuous Destitute Areas, Special-Contracted Teachers, Professional Development, Plight, Improvement Strategies

\section{Introduction}

China started to implement the special-contracted Teachers Scheme in 2006. By the end of September 2014, 423,000 special-contracted teachers have been distributed to rural primary and secondary schools across the country. Nowadays, researches on Special-Post teaeher in China are abundant, yet theories of teachers' Professional development and studies are relatively deficient. Based on field surveys of teachers' professional development, some authors endeavor to find out existing Problems, for example, the help TURA which obtains from departments of educational administration and schools is not so effective and practical; the professional development achievement of primary TURA is a little simplex; primary TURA on the whole is not active in professional development; the needs and ways of professional development of primary TURA mainly rely on others' help (Chen, 2014). Some researchers put forward measures and suggestions. For example, they create a good external environment to make teachers at ease in the labor of duty and strengthen teacher education training work to promote teachers grow up smoothly and strengthen the training for teachers to promote the development 
of the teachers (Liao, 2011). The author puts forward relevant suggestions from three directions as follows: hard environment for professional development of primary TURA, soft environment for professional development of primary TURA, cultivation of primary TURA (Chen, 2014) and plan of growth, promotes the special hillock teacher professional development, enhances the awareness of highly developed sense of self, and promotes the professional development of teachers (Wang, 2015). We should create the learning environment, establish the teachers learning community, strength the theoretical study and pay attention to exchange and reflection in the role of autonomous professional development (An, 2014). Since the scheme in 2006 in Guizhou province was implemented, 70,365 teachers have been recruited, accounted for $14.7 \%$ of the total number of special-contracted teachers in China. These teachers work in the primary and secondary schools in mountainous areas in Guizhou province. Both the teachers and the government have done their utmost to guarantee the implementation of this scheme. How is the professional development of the special-contracted teachers? It needs to be investigated. According to the investigation, the suggestions for the professional development of the special-contracted teachers are given.

\section{Methodology}

Special-contracted work in the primary and middle schools in the mountainous areas of Guizhou province, The investigation study on the professional development of teachers in Guizhou province adopts the method of cluster sampling and random sampling, From year 2006 to 2013 recruitment for special-contracted teacher (state, city) extraction five county (city, district), selected 5 junior high school, and 5 primary schools in each county. According to the different dimensions of the investigation, the research group designed two sets of questionnaires respectively, by the special-contracted teachers themselves (questionnaire 1), special-contracted in the school principal (two) were filled in. the research group designed two sets of questionnaires, respectively, which are filled in by the special-contracted teachers themselves (questionnaire 1), and the principals (two) of the school of the special-contracted teachers. 11 junior middle schools and 12 primary schools in the survey were extracted as samples from five different areas from Bijie, Tongren, Xingyi, Carey and Liupanshui. Questionnaires (a) filled by the special-contracted teachers, total 300 copies, with 274 of them collected, recovery rate as $91.3 \%$, 253 of them are valid questionnaires, among the teachers filled the questionnaires, the number of the male teachers are 119 (47\%), female teachers are 134 (53\%); the average age of the surveyed teachers is 25.51 years old, average teaching length is 2.57 years; The number of 2nd Grade Primary teachers are 63 (25\%), the number of 1st Grade Primary is 86 (34\%); The number of 3rd Grade junior middle schools teachers are 13 (5\%), The number of 2nd Grade junior middle schools teachers is 28 (11\%). Questionnaires are filled by 11 junior middle schools and 12 primary schools, the recovery rate and the effective rate both were $100 \%$. Questionnaires 1 mainly cover below five aspects: the working responsibilities, the difficulties in their work, their expectations for the professional supports and also their future career plans, the policies suggestions from them for the special contracted teachers. The questionnaires 2 are designed for the principals of the schools of the special contracted teachers, mainly cover below two aspects: the expectations from them for the valuation of the special contracted teachers' working abilities, also the policy suggestions to the special contracted teachers. The method used in the data analysis is the simple descriptive statistics.

\section{Survey Found}

\subsection{The High Degree of Professional Identity and the Strong Sense of Professional Development}

According to the results of the questionnaire, $28 \%$ of the teachers chose to be a special-contracted teacher because they love to be a teacher; $30 \%$ of the teachers did this to help the less developed areas to improve the education quality; $6 \%$ of the teachers intended to become a formal engaged teacher through this scheme. It is concluded that $64 \%$ of the teachers chose to be a special-contracted teacher because they love education. $97 \%$ of the teachers were willing to continually work as a teacher after the expiration of a three-year contract which coincides with the planned retention rate for the past 6 years. As for the reasons why they chose to continually work as teachers, $50 \%$ of the teachers claimed that they like teaching and love kids. $7 \%$ of teachers did this because they are satisfied with the salary. $8 \%$ of the teachers did this because they love working environment and atmosphere in schools. All in all, they chose special-contracted teacher as an occupation not simply for the purpose to find a job. The main reason is that they love to be teachers or they plan to improve the poor education situation in their hometown which shows that the special-contracted teachers from the destitute areas posses 
high degree of professional identity and fine professional identity is the drive for professional development.

\subsection{The Plight of Special-Contracted Teachers' Professional Development}

Special-contracted teachers in the continuous destitute areas face various plights concerning their professional development. 33\% of the teachers thought that the most difficult part was their lack of experience in student management. $30 \%$ of the teachers acknowledged that they lack flexible teaching methods in class which is the most commonly encountered problem for novice teacher. Consequently novice teachers are in need of help to solve the problem. $28 \%$ of the teachers attributed the difficulty to the lack of teaching facilities. $10 \%$ of the teachers thought that they posses solid professional knowledge, but they are weak in expressing themselves. 11\% of the headmasters thought that special-contracted teachers don't possess solid professional knowledge and their teaching skills are far from satisfactory. In a word, the professional development of special-contracted teachers in destitute areas is restricted by various factors.

\subsection{The Mismatch between Learning and Teaching as the Realistic Obstacle Hindering Special-Contracted Teachers' Professional Development}

Among all the teachers investigated, only 13\% teach the content they learned as their majors in colleges or universities. $17 \%$ of the teachers teach the content that has nothing to do with their majors. $40 \%$ of the teachers teach the content that sometimes coincides their majors and sometimes not. According to the current cultivation mode for students' majoring in education, graduates majoring in primary school education are allowed to work as general teachers. Students majoring in other areas of teacher education are admitted and cultivated according to their majors. There is no such thing as one major with multiple skills. No mode for training general teachers has been conducted. The application and distribution of Teachers' qualification certificates are also conducted according to different teaching subjects. The number of the teachers required in different subjects is clearly stated in every school in order to provide enough teachers for local schools so that the lectures can be delivered to students according to the teaching plan. However, in fact, $57 \%$ of the teachers taught the contents that didn't coincide with their majors; of all the subjects stated in teachers' qualification certificates, $60 \%$ of them were inconsistent with the subjects taught by the teachers. The mismatch between learning and teaching causes serious loss in teaching resources, and some skills are seriously devalued. Consequently, this problem becomes a real obstacle hindering special-contracted teachers' professional development.

\subsection{Heavy Teaching Tasks Seriously Restrain Teachers' Professional Development}

According to the investigation, $22 \%$ of the teachers teach two different subjects; $47 \%$ of the teachers teach three different subjects; $26 \%$ of the teachers teach at least four different subjects. Among all the teachers investigated, $38 \%$ attend eleven to fifteen class sessions every week; $36 \%$ attend sixteen to twenty class sessions every week; $6 \%$ attend twenty-one to twenty-five class sessions every week, and $6 \%$ attend more than 26 class sessions one week. $44 \%$ of the teachers have more work than they can handle. Some of them even attend more than 25 class sessions. The heavy teaching tasks occupied the time assigned to teaching design and teaching improvement. There is no denying that teaching design requires a lot of time and energy especially for novice teachers, because teaching design is closely related to the teaching quality and teaching efficiency in classroom.

\subsection{Non-Teaching Activities Hinder Teachers' Professional Development}

It is stated in Medium- and Long-term Plan for Education in Guizhou province, that by the end of 2015, the boarding rate in rural primary school will reach $30 \%$ and the boarding rate in rural secondary school will reach $70 \%$, based on the actual demand, the near-by enrollment policy and the relatively centralized school sponsoring model. By the year 2020, rural secondary school students' accommodation requirements will all be met. The primary and secondary boarding schools in Guizhou province mainly carry out totally enclosed collective management. Meanwhile, the number of the teachers can hardly meet the needs, so teachers' workload will be doubled. Since the spring of 2012, schools in Guizhou province fully implanted the policy of offering students nutritious meals with Guizhou characteristics. This policy has benefited 3,780,000 students from 87 counties. Students must accompanied by teacher to have the nutritious lunch and then supervised by teachers while they take noon breaks. Teachers are responsible for student safety. The implementation of the nutritious meal policy 
undoubtedly increased teachers' workload. However, the number of the staff members in each compulsory education school is 0.05 . Questionnaires shows that teachers stay at school for dinner with students, management of the students' safety at noon on average every week 2 days, According to the survey, boarding school teachers need boarding school once a week. The full-time teachers have to take care of students' daily life, which requires the energy used for teaching. Non-teaching activities seriously hinder teachers' professional development.

\subsection{School Teaching Facilities Are Outdated and Advanced Educational Concepts Are Difficult to Achieve}

Special-contracted teachers in education and teaching are longing for the support of high-quality teaching resources. Young special-contracted teachers have realized the value of high-quality teaching resources for improving teaching efficiency. Therefore, they are eager to have the high-quality teaching resources to assist classroom teaching. However, $28 \%$ of them argue that the lack of teaching facilities cannot meet the needs of everyday teaching. In Wumeng contiguous destitute of Bijie Prefecture, the proportion of primary schools with enough sports equipment was $75.2 \%$, while among junior high schools, it is $75.5 \%$. The proportion of schools with enough musical instruments was respectively $73.7 \%$ and $74 \%$. For art instruments, the proportion is respectively $73.6 \%$ and $72.7 \%$. For natural experiment apparatus of mathematics, the proportion is $77.1 \%$. The proportion of junior middle schools with enough science laboratory equipment is $76.3 \%$. For schools that have established campus network, the proportion is respectively $11.7 \%$ and $44.6 \%$. In conclusion, the existing teaching conditions in poor areas cannot meet the needs of modern teaching and advanced educational concepts are difficult to achieve.

\subsection{Vague Incentives and Less Efficient Restriction Mechanisms}

The recruitment policy of special-contracted teachers provide young people more favors to determine whether to stay or not after fulfilling three-year duty. 17 percent of them chose to be special-contracted teachers because of the difficulties to find more proper jobs, so they turned to it as a transitional job. Once finished their duty, 3 percent of them determined to leave as they endeavored to prepare to get another job while taught there. As to the young people, the profession is just a transitional one. However, from the aspect of personnel turnover, the special-contracted teachers are trying to change their fate, which is quite encouraging. Since being a teacher is required to be responsible and endurable for difficulties. If one were busy with preparing to the personal examinations that are distant from teaching contents, he might be distracted rather than putting more efforts to teach. Besides, teachers who are busy with preparing to their personal exams would lead to the complaints from those responsible teachers and in that case, it would bring negative effects to their relations.

\subsection{Lack of the Joint Environment for the Improvement of Special-Contracted Teachers}

Due to the poor teaching quality of compulsory in the impoverished areas of west region, the newly recruited special-contracted teachers have to face a poor environment like that, therefore, the improvement of them are bound to slow down. As a major part of learning outcomes, to some extent, the academic performance of students is a reflection of teachers' levels. In the research, 28 percent of the teachers' classes got their score between 60 and 69 in the final exam while a 21 percent of their classes did not pass it. When got troubles in teaching, 64 percent of the new special-contracted teachers chose to turn to school resources such as their colleagues, other qualified special-contracted teachers or the school leaders. Some qualified ones pointed that the quality of new special-contracted teachers cannot lead the needs and development of the profession. In addition, the schools are short of teaching resources, the new teachers explore their own way in practices without the help of qualified teachers and the school trainings are difficult to go whereas with a poor level. All these problems lead to the anxiety and helplessness of new special-contracted teachers then they consider it as a wrong profession and they may be hesitated to decide to leave or not.

\subsection{The Deficiency of Teachers' Professional Knowledge and Skills Restricted Their Development}

The deficiency of the special-contracted teachers' professional knowledge and skills restricted their own development. According to the research, 11 percent of the special-contracted teachers clearly realized their deficiency 
in professional and teaching knowledge. During the practices, 26 percent of them still taught for the tests and individually added or deleted some contents of textbooks to meet the tests requirements. 13 percent of them completely taught in accordance with textbooks. 26 percent of them had a poor classroom teaching efficiency, they rarely finished the classroom teaching tasks and had to make up lessons to achieve them. 52 percent of the teachers barely finished their tasks. From the above, we can learn that some of the special-contracted teachers are not qualified in a broad and deep level of professional knowledge. With the absent of some professional knowledge, it will be quite difficult to comprehend the classroom teaching contents, let alone dominantly analysing teaching tasks to reduce teaching difficulty and taking the acceptable ways to teach students well.

\section{Measures to Improve the Professional Level of Special-Contracted Teachers in Impoverished Areas}

\subsection{Improve the Pre-Post Training of Teachers and Training Contents to Develop Professional Skills of the Teachers in Rural Areas}

As the research shows, 32 percent of special-contracted teachers are in great need to achieve classroom teaching methods and skills. 26 percent of them need to get the management way of classes. The top two of the greatest in need of the special-contracted teachers in training are class management and classroom teaching methods. But in the training, teachers mostly need to listen without expressing. Because the short period of the training, it more likes the mobilization meeting and the training contents are all general knowledge about education, with a large number of training teachers, it has to be done in large lecture classes which is hard to meet the specific needs of teachers. The trainers are usually executive officers, staff in education department or the college teachers. They are not familiar with the conditions of primary and secondary schools, and often talk more about mobilizations and theories. Sometimes they mentioned about the subject teaching skills but only in the level of theory. As a result, it will be difficult for pre-service teachers without teaching experience to get the key points of the theory. We need to improve the training contents and start from the problems in teaching practices, taking active actions to carry out the training by the means of cases teaching and videos teaching so as to improve the professional skills of teachers in rural areas.

\subsection{Upgrade the Teaching and Research Convention on Class Observation and Comment by the Way of MOOC}

One of the goals of special-contracted plan is to resolve the urgent needs of the teachers in rural areas. Therefore, it's very difficult for the special-contracted teachers to skive their work to improve themselves in 3-year service. Facing with a large number of pre-training teachers, we need to take the way of MOOC to upgrade the teaching and research convention on class observation and comment. MOOC is the abbreviation of Massive (large scale), Open (open), Online (online), Course (course), which means the large-scale network open course. It is composed of many learners who are willing to share and collaborate in order to enhance the knowledge. Try to integrate various channels to explore the teaching training practices of MOOC. Through multiple ways of cooperation, build up high-quality online school gateways or invite IT professionals to record high-quality micro video lessons so as to share them with the primary and secondary schools. We also need to take use of the internet to make the local teachers communicate with each other and deeply cooperate and interact with prominent teachers from various places, so that the pre-service teachers can learn improve themselves in practices.

\subsection{Take Good Use of Local College Resources to Build a High-Level Collaborative Innovation Center}

The awareness and skills of teachers in continuous learning and teaching research are the driving forces for their development in career life. Take good use of local college resources to build a high-level collaborative innovation center so as to provide a platform for the transformation of the driving forces (Pang \& Hong, 2011). When participating in the guidance of college teachers and professional development activities, teachers in primary and secondary schools need to comprehensively learn the characters of subjects, curriculum standards, characters and purpose of education quality evaluation indexes etc. so that to make the teaching practices more targeted and scientific. By virtue of progressive educational ideas of college teachers, primary and secondary school teachers ought to inspect their confusions in teaching and the current educational situation, rethink the problems 
in teaching, analyze the educational notes, improve the involved theories and use them to enrich the practical knowledge.

\section{Conclusion}

Even though special-contracted teachers possess high degree of professional identity and strong sense of professional development, their professional development is still impeded by some factors, like teaching related and non-teaching related activities and the mismatch between teaching and learning. Meanwhile, their professional development is hindered by other factors, for example, poor infrastructure, unclear professional motivation, lack of effective constraint mechanism, lack of professional development community, personal subject content knowledge and inadequate capacity. This paper attempts to propose several strategies to improve the current situation: improve pre-service training, optimize the content of training, cultivate rural teachers' professional ability, employ the MOOC mode, innovate the mechanism to observe and evaluate classes, vitalize the resources of colleges and universities and create advanced collaborative innovation center.

\section{Acknowledgements}

This paper is financed by the Bidding Project of Education reform and Development in 2012 in Guizhou province: "special-contracted teachers" policy on the development of rural education in Guizhou province research on policy optimization

This paper is financed by the Project of Bijie University: research on the teaching quality of the compulsory education in Bijie. Item number 20081010.

\section{References}

Chen Y. J. (2014). An Research on the Professional dP Development of TURA and It's Factors-Take Three Counties in Guangxi Province for Example. Master Degree Thesis, Chongqing: Chongqing Normal University.

Liao, Z. H. (2010). Survey on the Situation of special-contracted Teachers in Rural Areas of the West Region-A Case Study of Ludian County in Yunnan Province. Elementary Education, 4, 6.

An, F. H. (2014). The Problems and Solutions for the Professional Development of Special-Contracted Teachers-A Case Study on Weining County in Guizhou and Laiyuan County in Hebei. Theories and Practices of Education, 4, 6 p.

Pang, L. J., \& Hong X. M. (2011). Crack Teachers' Teaching Problems: A Cooperation of the Government, Universities and Primary and Secondary Schools. Shenyang Normal University Press (The social Science Edition), 2, 1-3. 